\title{
A hierarchy of time scales supports unsupervised learning of behavioral sequences
}

\author{
Samuel P Muscinelli, Wulfram Gerstner \\ From 24th Annual Computational Neuroscience Meeting: CNS*2015 \\ Prague, Czech Republic. 18-23 July 2015
}

Playing the piano, speaking or playing tennis are just few examples of behavioral situations in which we need to perform sequences of actions. The neurophysiological mechanisms that underlie the production and learning of such sequences are far from being understood and several crucial issues arise in biologically plausible models: first, there is a huge gap of time scales between the response of single neurons, which is on the order of tens of milliseconds, and common behavioral situations, which usually span several seconds. Moreover, behavioral sequences are often complex, i.e. they cannot be described as Markov chains and thus require to relate distant parts of the sequence. Finally, similar to its biological counterpart, a candidate model should be able to learn new sequences with biologically plausible learning rules.

We devise a simplified model of neural populations with the aim of producing slow sequences of neural activation to correlate with behavioral sequences. We exploit spike frequency adaptation of single neurons to introduce a slow process [1] in the population dynamics in order to fill the gap between different time scales described above. Our model features a hierarchy of time scales inspired by evidence of different time scales among different areas in the brain $[2,3]$. This allows a separation of neural coding into varying levels of temporal detail: the sequence produced in a "faster" area will be regulated by the activity of "slower" areas in a hierarchical fashion. This provides a mechanism to deal with non-Markovianity thanks to the longer memory capacity of "slower" areas. Finally, we show that it is possible to learn the appropriate inter-area synaptic connections using biologically plausible learning rules, exploiting the decrease in activity due to adaptation.

\footnotetext{
* Correspondence: samuel.muscinelli@epfl.ch

School of Life Sciences, Brain Mind Institute and School of Computer and Communication Sciences, École Polytechnique Fédérale de Lausanne, 1015
} Lausanne, Switzerland

Submit your next manuscript to BioMed Central and take full advantage of:

- Convenient online submission

- Thorough peer review

- No space constraints or color figure charges

- Immediate publication on acceptance

- Inclusion in PubMed, CAS, Scopus and Google Scholar

- Research which is freely available for redistribution

Submit your manuscript at Submit your manuscript at
www.biomedcentral.com/submit C BioMed Central 